\title{
Case Report for Two Hemodialysed Patients Diagnosed for COVID-19 at the Donka National Hemodialysis Center
}

\author{
Mamadou Saliou Baldé ${ }^{*}$, Abdoulaye Touré2, Amadou Yalla Camara3 ${ }^{3}$ Joseph Donamou ${ }^{3}$, \\ Aly Traoré1, Boubacar Atigou Drame ${ }^{2}$, M'mah Lamine Camara ${ }^{3}$, Almamy Bangoura², \\ Mariam Mohamed Camara ${ }^{3}$, Mohamed Lamine Kaba ${ }^{1}$ \\ ${ }^{1}$ Department of Nephrology-Hemodialysis, Hospital National Donka, Conakry, Guinea \\ ${ }^{2}$ Department of Reanimation, Hospital Ignace Deen, Conakry, Guinea \\ ${ }^{3}$ Department of Reanimation, Hospital National Donka, Conakry, Guinea \\ Email: *baldenephro@gmail.com
}

How to cite this paper: Baldé, M.S., Touré, A., Camara, A.Y., Donamou, J., Traoré, A., Drame, B.A., Camara, M.L., Bangoura, A., Camara, M.M. and Kaba, M.L. (2020) Case Report for Two Hemodialysed Patients Diagnosed for COVID-19 at the Donka National Hemodialysis Center. Open Journal of Nephrology, 10, 241-244.

https://doi.org/10.4236/ojneph.2020.103023

Received: July 24, 2020

Accepted: August 24, 2020

Published: August 27, 2020

Copyright $\odot 2020$ by author(s) and Scientific Research Publishing Inc. This work is licensed under the Creative Commons Attribution International License (CC BY 4.0).

http://creativecommons.org/licenses/by/4.0/

\begin{abstract}
In December 2019, coronavirus disease (COVID-19) due to infection with the novel SARS-CoV-2 virus began to break out. Hemodialysis patients are at high risk because of the co-morbidities. We report the clinical and biological characteristics of two patients who developed COVID-19 infection in our dialysis center in Donka National Hospital. None of the patients had contact with an infected person. The age was 38 and 54 years. The symptoms common to both patients were: fatigue, diarrhea, fever. Lymphopenia was present in both patients. None of them had a chest X-ray or chest scan because they were positive for the test before admission.
\end{abstract}

\section{Keywords}

Hemodialysis, COVID-19, Coronavirus, Donka

\section{Introduction}

In December 2019, coronavirus disease (COVID-19) due to infection with the novel SARS-CoV-2 virus began to break out [1]. Research on the origin of SARS-CoV-2 focused on the bat [2]. There is no antiviral medication at this time that has proven effective against this infection or a vaccine. In life-threatening situations, some patients require respiratory assistance. There is limited data to date on COVID-19 infection in hemodialysis patients in Africa. Hemodialysis patients are at high risk because of comorbidities [3]. For 
reporting this case, the patients are informed and we have consent from the 2 patients. We report our experience of two hemodialysed patients who are positive for COVID-19.

\section{Report on the 2 Cases}

Out of a total of 193 hemodialysis patients, 2 were diagnosed with COVID-19 infection, the test by reverse transcriptase PCR for SARS-CoV-2 (rRT-PCR) returned positive. The characteristics of these 2 patients are presented in Table 1. The age was 38 and 54 years, both are men. None of the 2 patients had any notion of direct contact with an infected person, no family member was infected. Common symptoms of infection were: diarrhea (1/2), followed by fever $(2 / 2)$, fatigue (2/2) dyspnea (2/2) and abdominal pain (2/2). Only one patient had a dry cough. One patient complained of a dry throat, none of them had rhinorrhea, they had severe asthenia and myalgia, and they did not have respiratory distress. All 2 patients had lymphopenia $\left(<1.0 \times 10^{9} / \mathrm{L}\right)$. All 2 patients were hospitalized in a reanimation COVID in Donka National Hospital and subjected to hydroxychloroquine $200 \mathrm{mg}$ ( 1 tablet 3 times a day); Erythromycin $500 \mathrm{mg} 1$ tablet the first day then $1 / 2$ tablet from $2^{\text {nd }}$ to $5^{\text {th }}$ day; KALETRA (lopinavir 200 $\mathrm{mg} /$ Ritonavir $50 \mathrm{mg}$ ) one tablet once a day; dexamethasone injectable $20 \mathrm{mg}$ from $1^{\text {st }}$ day to $5^{\text {th }}$ day then $10 \mathrm{mg} /$ day from $6^{\text {th }}$ to $10^{\text {th }}$ day and $4 \mathrm{mg} /$ day from $11^{\text {th }}$ to $14^{\text {th }}$ day; cefotaxime $1 \mathrm{~g} 2$ times a day intravenously; Enoxaparin 8000 IU/J; vitamin C $1000 \mathrm{mg} / \mathrm{J}$, Zinc 2 tablet per day. They were declared cured for COVID-19 after 25 days of hospitalization by the same test. At the end of this study, the patient's age of 54 years developed acute respiratory syndrome because of the sequelae of COVID in his lung. Now he is following in respiratory disease department.

\section{Discussion}

We described 2 patients in our dialysis center who were diagnosed with COVID-19, representing a frequency of $1.03 \%$ at this time. The 2 patients presented with lymphopenia to the blood count, they could not do the chest X-ray and the chest CT because the test being positive and the two patients did not present a pulmonary sign at the arrival. We did not systematically screen all patients and caregivers due to the lack of screening kites. We monitored the temperature for all the staff. Immune cells have been shown to play a large role in the recovery from SARS-CoV infection [4]. Because the uremic state is associated with a dysregulation of the lymphocyte and granulocytic function, therefore a drop in the immune system could reduce the response to SARS-CoV infection [4]. Dialysis center needs a special attention given the number of people on hemodialysis and who represent a population at high risk. In our case, we do not have a large spread of the virus in our center because we implemented preventive measures very early. We recommend all patients and medical staff to wear face mask before entrance and exit the center. 
Table 1. Clinical and biological of patients.

\begin{tabular}{lll}
\hline & Patient 1 & Patient 2 \\
\hline Clinical & & \\
\hline Age (years) & 54 & 38 \\
Sex & M & M \\
History of contact with a person infected & NO \\
Family member infected & NO & NO \\
Hemodialysis duration (years) & 2 & 4 \\
Initial Nephropathy & GNC & NAS \\
Diabètes & NO & NO \\
\hline Symptom and Sign & & \\
\hline - Fever & Yes & Yes \\
- Dry cough & Yes & NO \\
- Dyspnea & Yes & Yes \\
- Fatigue & Yes & Yes \\
- Diarrhea & Yes & Yes \\
- Abdominal Pain & Yes & Yes \\
\hline Biology & 2.62 & 2.80 \\
\hline - Total WBC count $\times 10^{9} / \mathrm{L}$ & 0,6 & 0.53 \\
- Neutrophils $\times 10^{9} / \mathrm{L}$ & & 25 \\
- Lymphocytes $\times 10^{9} / \mathrm{L}$ & & \\
hospitalisation Time in COVID Reanimation $($ day) & & \\
\hline & & \\
\hline
\end{tabular}

We have prohibited regrouping at the center without distancing. During dialysis session, we recommended the wearing of personal protective equipment (PPE). After the hemodialysis session, the machine and the room are disinfected with a hydrochloric solution, then all the medical equipment.

In a retrospective study of 1099 patients with acute respiratory distress due to COVID-19, fever and cough were the dominant symptoms whereas vomiting and diarrhea were rare [5]. Wang et al. found that the most common symptoms were fever, fatigue and dry cough and some patients had gastrointestinal symptoms such as nausea and diarrhea [6]. In our case was present, cough, fever, dyspnea, fatigue, diarrhea, abdominal pain. Many symptoms in dialysis patients with COVID-19 are difficult to distinguish from other symptoms in dialysis patients in general. In this case, we can conduct hemodialysis for patient positive with COVID-19 in a very limited resource country (West Africa), only by respecting the rule we learned by COVID-19 outbreak in Asia and Europe.

\section{Conclusion}

We have described the case of 2 patients who developed COVID-19. In addition 
to fever and fatigue, diarrhea was very common in the 2 patients, and further investigation would be necessary to fully understand the clinical aspect of COVID-19 in dialysis patients and optimal treatment of COVID-19 in dialysis patients.

\section{Conflicts of Interest}

The authors declare no conflicts of interest regarding the publication of this paper.

\section{References}

[1] Walker, L.J. (2020) COVID-19, Australia: Epidemiology Report 2 (Reporting Week Ending 19:00 AEDT 8 February 2020). Communicable Diseases Intelligence, 44. https://doi.org/10.33321/cdi.2020.44.14

[2] Hui, D.S., Azhar, E.I. and Madani, T.A., et al. (2020) The Continuing 2019-nCoV Epidemic Threat of Novel Coronaviruses to Global Health-The Latest 2019 Novel Coronavirus Outbreak in Wuhan, China. International Journal of Infectious Diseases, 91, 264-266. https://doi.org/10.1016/j.ijid.2020.01.009

[3] Ikizler, A. (2020) COVID-19 and Dialysis Units: What Do We Know Now and What Should We Do? American Journal of Kidney Diseases, 76, 1-3. https://doi.org/10.1053/j.ajkd.2020.03.008

[4] Zhou, J., Li, C., Zhao, G., et al. (2017) Human Intestinal Tract Serves as an Alternative Infection Route for Middle East Respiratory Syndrome Coronavirus. Science Advances, 3, o4966. https://doi.org/10.1126/sciadv.aao4966

[5] Guan, W.-J., Ni, Z.-Y. and Hu, Y. (2020) The China Medical Treatment Expert Group for COVID-19: Clinical Characteristics of 2019 Novel Coronavirus Infection in China. [Epub Ahead of Print February 28, 2020]

[6] Wang, D, Hu, B., Hu, C., et al. (2020) Clinical Characteristics of 138 Hospitalized Patients with 2019 Novel Coronavirus-Infected Pneumonia in Wuhan, China. JAMA, 323, 1061-1069. https://doi.org/10.1001/jama.2020.1585 